\title{
PERAN PERAWAT DALAM PROMOSI DAN EVALUASI PENERAPAN BUDAYA KESELAMATAN PASIEN \\ Junimiserya Zalukhu \\ junimiserya01@gmail.com
}

\begin{abstract}
ABSTRAK
Rumah sakit sebagai sarana pelayanan kesehatan pada dasarnya adalah untuk menyelamatkan pasien, keselamatan pasien merupakan prioritas penting di rumah sakit. Langkah awal dalam mencapai keselamatan pasien tersebut adalah melalui penerapan budaya keselamatan pasien yang disertai kepemimpinan yang baik. Budaya keselamatan pasien merupakan hal penting dari berbagai upaya untuk meningkatkan keselamatan pasien dan mempengaruhi kualitas pelayanan kesehatan. Budaya keselamatan adalah nilai, keyakinan, perilaku yang dianut individu dalam suatu organisasi mengenai keselamatan yang memprioritaskan dan mendukung peningkatan keselamatan. Namun, penerapan keselamatan pasien jauh dari standar karena para tenaga kesehatan belum memiliki budaya keselamatan pasien yang terinternalisasi dalam diri mereka. Sehingga perlu dilakukan upaya untuk menanamkan budaya keselamatan pasien dengan cara promosi budaya keselamatan itu sendiri. Selain itu, dalam membangun budaya keselamatan, sangat penting bagi rumah sakit untuk mengukur perkembangan budaya dengan melakukan evaluasi budaya keselamatan secara berkala. Pengukuran pertama sangat penting sebagai data dasar yang akan dipergunakan sebagai acuan penyusunan program keselamatan pasien.
\end{abstract}

Kata Kunci : budaya keselamatan pasien, promosi budaya keselamatan, evaluasi budaya keselamatan, keselamatan pasien.

\section{LATAR BELAKANG}

Kebijakan kesehatan di berbagai negara juga menekankan pada penilaian dan peningkatan kualitas pelayanan kesehatan serta keselamatan pasien yang merupakan faktor utama dalam memperbaiki kualitas pelayanan kesehatan (Chen, Ng \& Li 2012).
Keselamatan pasien di rumah sakit melibatkan partisipasi dari semua petugas kesehatan, terutama perawat. Perawat sebagai salah satu tenaga kesehatan yang mempunyai jumlah cukup dominan di rumah sakit yaitu sebesar 50 sampai $60 \%$ dari jumlah tenaga kesehatan yang ada. Pelayanan asuhan keperawatan yang 
diberikan kepada pasien merupakan pelayanan yang terintegrasi dari pelayanan kesehatan yang lainnya dan memiliki peran yang cukup penting bagi terwujudnya kesehatan dan keselamatan pasien.

Budaya keselamatan pasien merupakan hal penting dari berbagai upaya untuk meningkatkan keselamatan pasien dan mempengaruhi kualitas pelayanan kesehatan. Beberapa penelitian menunjukkan bahwa budaya keselamatan pasien dan konsep terkait keselamatan sangat berhubungan erat dengan perilaku tenaga kesehatan, pengurangan efek samping, kesalahan pemberian obat (medication error), insiden keparahan, angka cedera petugas kesehatan karena jarum suntik dan paparan patogen (Feng et al. 2011; Weaver et al. 2013).

Banyak kegiatan yang difokuskan untuk mempromosikan budaya keselamatan, namun pemahaman mengenai faktor implementasi yang paling efektif yang dapat mempengaruhi efektivitas merupakan hal penting untuk mencapai kemajuan yang signifikan (Weaver et al. 2013).

Budaya keselamatan pasien dapat diartikan sebagai bagian dari aspek budaya organisasi, dalam hal ini organisasi manajemen di rumah sakit (RS). Budaya tersebut dianggap sebagai sikap, nilai, keyakinan, persepsi, norma, kompetensi, dan prosedur terkait dengan keselamatan pasien (Chen, Ng \& Li 2012; Weaver et al. 2013). Budaya juga membentuk tenaga kesehatan mengenai perilaku yang normal terkait dengan keselamatan pasien di wilayah kerja mereka. Oleh karena itu, budaya mempengaruhi motivasi seseorang untuk terlibat dalam perilaku aman dan sejauh mana motivasi ini diterapkan dalam praktek sehari-hari (Weaver et al. 2013).

Management safety commitment merupakan faktor kunci dalam mempengaruhi lingkungan keselamatan organisasi. Komitmen keselamatan dari manajemen dibuktikan melalui kebijakan tertulis, komunikasi yang efektif, dan teladan praktek (Feng et al. 2011). Organisasi menjadi sadar akan pentingnya transformasi organisasi budaya dalam rangka meningkatkan keselamatan pasien (Chen, Ng \& Li 2012).

Langkah yang dapat digunakan untuk mempromosikan budaya keselamatan pasien dalam pelayanan kesehatan, menilai efektivitas langkah tersbeut dan hasil yang dirasakan pasien serta mempelajari hubungan antara komitmen manajemen mengenai keselamatan pasien dan budaya keselamatan pasien di Indonesia. 


\section{METODE}

Metode penelitian yang dilakkan

adalah literature review. Literature review ini menganalisis jurnal, text book, dan ebook yang relevan dengan topik pembahasan yaitu Peran Perawat Dalam Promosi dan Evaluasi Penerapan Budaya Keselamatan Pasien. Referensi akan dicantumkan dengan jelas di daftar pustaka pada bagian akhir kajian. Jurnal,text book, dan ebook yang digunakan adalah yang diterbitkan 8 tahun terakhir.

\section{HASIL}

Berdasarkan kajian literature, budaya keselamatan pasien merupakan hal penting dari berbagai upaya untuk meningkatkan keselamatan pasien dan mempengaruhi kualitas pelayanan kesehatan. Budaya keselamatan adalah nilai, keyakinan, perilaku yang dianut individu dalam suatu organisasi mengenai keselamatan yang memprioritaskan dan mendukung peningkatan keselamatan.

Namun, penerapan keselamatan pasien jauh dari standar karena para tenaga kesehatan belum memiliki budaya keselamatan pasien yang terinternalisasi dalam diri mereka. Sehingga perlu dilakukan upaya untuk menanamkan budaya keselamatan pasien dengan cara promosi budaya keselamatan itu sendiri. Pelatihan tim dan executive walk rounds merupakan strategi intervensi yang cukup bermakna untuk mempromosikan keselamatan pasien

Selain itu, dalam membangun budaya keselamatan, sangat penting bagi rumah sakit untuk mengukur perkembangan budaya dengan melakukan evaluasi budaya keselamatan secara berkala. Pengukuran pertama sangat penting sebagai data dasar yang akan dipergunakan sebagai acuan penyusunan program keselamatan pasien. Evaluasi budaya keselamatan bisa dengan menjadikan Dimensi Budaya Keselamatan Pasien menjadi tolak ukurnya melalui 12 dimensi keselamatan pasien yang dikeluarkan oleh AHRQ (American Hoaspital Research and Quality) mengenai isue keselamatan pasien

\section{PEMBAHASAN}

Keselamatan pasien di Indonesia masih belum menjadi prioritas utama dalam pelayanan kesehatan jika dibandingkan dengan negara tetangga (Singapura dan Malaysia). Namun dalam beberapa tahun terakhir ini, keselamatan pasien mulai menjadi fokus perhatian seiring dengan tuntutan akreditasi RS standar Joint Commission International (JCI). Namun, penerapan keselamatan pasien jauh dari standar karena para tenaga kesehatan belum memiliki budaya 
keselamatan pasien yang terinternalisasi dalam diri mereka.

Sehingga perlu dilakukan upaya untuk menanamkan budaya keselamatan pasien dengan cara promosi budaya keselamatan itu sendiri.

\section{a. Promosi Budaya Keselamatan}

Promosi budaya keselamatan pasien dapat dikonseptualisasikan melalui prinsip-prinsip kepemimpinan, kerjasama tim, dan perubahan perilaku. Strategi untuk mempromosikan budaya keselamatan pasien dapat dilakukan secara intervensi tunggal atau kombinasi dari beberapa intervensi. Pelatihan tim dan executive walk rounds merupakan strategi intervensi yang cukup bermakna untuk mempromosikan keselamatan pasien (Weaver et al. 2013)

Pelatihan tim mengacu pada metode terstruktur untuk mengoptimalkan proses kerja tim, seperti komunikasi, kerjasama, kolaborasi, dan kepemimpinan. Executive walk rounds merupakan strategi intervensi yang melibatkan kepemimpinan organisasi secara langsung dengan garis depan penyedia layanan kesehatan. Pemimpin mengunjungi area perawatan pasien dengan tujuan mengamati dan mendiskusikan ancaman potensial terhadap keselamatan pasien. Hal ini bertujuan menunjukkan komitmen kepemimpinan untuk keselamatan, meningkatkan kepercayaan dan keamanan psikologis, serta memberikan dukungan kepada tenaga kesehatan untuk proaktif mengatasi ancaman keselamatan pasien (Weaver et al. 2013).

Hasil systematic review oleh Weaver et al. (2013) dilaporkan bahwa setelah dilakukan pelatihan tim terdapat perbaikan dalam proses perawatan yaitu keterlambatan pelayanan yang menurun dan peningkatan penggunaan komunikasi yang terstruktur. Terdapat pula perbaikan hasil keselamatan pasien yaitu kesalahan yang mengakibatkan kerugian menurun atau pengurangan indeks hasil yang merugikan. Hasil yang sama juga didapatkan setelah dilakukan executive walk rounds, yaitu didapatkan perbaikan persepsi staf pada keselamatan pasien terutama persepsi terhadap proses perawatan dan hasil keselamatan pasien. Namun terdapat tantangan penting mengenai cara untuk melatih perawat dan memastikan perawat mempertahankan kompetensi serta meminimalkan potensi bahaya. Para pendidik dibidang medis menganggap model pelatihan medis tradisional "see one, do one, teach one" sebagai suatu model pelatihan yang tidak terstruktur dan tidak memadai (Schmidt et al. 2013). Sehingga perlu dipikirkan model pelatihan lain yang lebih tepat, salah 
satunya adalah simulation exercises (latihan simulasi).

Latihan simulasi memungkinkan perawat dan tenaga kesehatan lainnya untuk melakukan pelatihan yang aman dan dapat berfungsi untuk mempertahankan keterampilan klinis serta menjadi bagian dari sertifikasi. Latihan simulasi harus dirasakan nyata oleh peserta sehingga dapat menghilangkan ketidakpercayaan, membuat peserta merasakan, berpikir, dan bertindak sesuai dengan skenario. Melalui latihan simulasi ini diharapkan dapat meningkatkan keselamatan pasien yang memungkinkan perawat untuk menjadi lebih terlatih tanpa membuat pasien berisiko atau merugikan pasien. Latihan simulasi untuk meningkatkan keselamatan pasien memiliki 4 tujuan umum, yaitu pendidikan (continuing education), penilaian (quality control/improvement, atau pengujian kegunaan), penelitian (perilaku perawat), dan integrasi sistem kesehatan (proses tim) (Schmidt et al. 2013).

Salah satu masalah penting yang lain dalam keselamatan pasien adalah adverse events (efek samping). Efek samping merupakan hasil yang tidak diinginkan yang dianggap berasal dari perawatan medis daripada proses penyakit yang mendasari. Efek samping terjadi karena risiko yang terkait dengan terapi (operasi atau obat). Efek samping juga dapat terjadi karena kesalahan dalam desain sistem kesehatan atau kesalahan individu (Forster et al. 2012). Oleh karena itu, perlu ditetapkan strategi untuk mendeteksi efek samping yang tidak diinginkan sehingga dapat meningkatkan perbaikan keselamatan pasien.

Sistem kesehatan umumnya menggunakan 2 metode dalam melakukan strategi deteksi efek samping, yaitu voluntary reporting dan proactive surveillance. Voluntary reporting disebut juga pelaporan insiden merupakan metode yang banyak digunakan di RS namun kurang efektif. Metode ini melibatkan petugas kesehatan secara sukarela melaporkan insiden atau kejadian dengan menggunakan formulir secara elektronik maupun tertulis. Metode proactive surveillance melibatkan pemantauan secara aktif terhadap kejadian efek samping. Terdapat beberapa metode dalam proactive surveillance antara lain medical record review, administrative surveillance, clinical observation, dan eTrigger surveillance. Pasien dipantau untuk mengidentifikasi adanya kejadian yang mengarah pada poor outcome. Pada metode ini, poor outcome dipantau untuk ditentukan kemungkinan penyebabnya. Jika hasil tersebut disebabkan oleh perawatan medis, maka itu dianggap 
sebagai adverse events (Forster et al. 2012).

Strategi promosi budaya keselamatan untuk meningkatkan keselamatan pasien dapat dilakukan dengan berbagai cara. Beberapa cara yang cukup efektif adalah pelatihan tim, executive walk rounds, dan simulation exercises yang terbukti efektif dapat meningkatkan budaya keselamatan pasien. Selain itu dapat diterapkan metode untuk mendeteksi adanya adverse events untuk mencegah poor outcome yang berpotensi dapat merugikan pasien. Metode yang dapat dilakukan antara lain dengan cara voluntary reporting dan proactive surveillance.

\section{b. Evaluasi Budaya Keselamatan}

Keselamatan pasien merupakan komponen terpenting dalam mutu pelayanan kesehatan. Rumah sakit sebagai organisasi pelayanan kesehatan harus mampu meningkatkan keselamatan pasien dengan mengusahakan terwujudnya budaya keselamatan.

Dalam membangun budaya keselamatan, sangat penting bagi rumah sakit untuk mengukur perkembangan budaya dengan melakukan evaluasi budaya keselamatan budaya secara berkala. Pengukuran pertama sangat penting sebagai data dasar yang akan dipergunakan sebagai acuan penyusunan program keselamatan pasien.

Survey Budaya Keselamatan Pasien Rumah Sakit (Hospital Survey on Patient Safety Culture),dikeluarkan oleh AHRQ (American Hoaspital Research and Quality) mengenai isue keselamatan pasien, medical errors, dan pelaporan insiden. Survey ini terdiri atas 42 item yang mengukur 12 dimensi keselamatan pasien.

Dimensi Budaya Keselamatan Pasien

1. Komunikasi terbuka : Staf bebas berbicara ketika mereka melihat sesuatu yang berdampak negatif bagi pasien dan bebas menanyakan masalah tersebut kepada atasan

2. Komunikasi dan Umpan Balik :mengenai insiden Staf diberi informasi mengenai insiden yang terjadi, diberi umpan balik mengenai implementasi perbaikan, dan mendiskusikan cara untuk mencegah kesalahan

3. Frekuensi pelaporan insiden :Kesalahan dengan tipe berikut ini dilaporkan:

(1)kesalahan diketahui dan dikoreksi sebelum mempengaruhi pasien (2)kesalahan tanpa potensi cedera pada pasien (3)kesalahan yang dapat mencederai pasien tetapi tidak terjadi

4. Handoffs dan Transisi : Informasi mengenai pasien yang penting dapat dikomunikasikan dengan baik antar unit dan antar shift.

5. Dukungan managemen untuk keselamatan pasien Managemen rumah 
sakit mewujudkan iklim bekerja yang mengutamakan keselamatan pasien dan menunjukkan bahwa keselamatan pasien merupakan priotitas utama

6. Respon nonpunitif (tidak menghukum) terhadap kesalahan : Staf merasa kesalahan dan pelaporan insiden tidak dipergunakan untuk menyalahkan mereka dan tidak dimasukkan kedalam penilaian personal

7. Pembelajaran organisasi Peningkatan berkelanjutan : Kesalahan dipergunakan untuk perubahan kearah positif dan perubahan dievaluasi efektifitasnya

8. Persepsi keselamatan pasien secara keseluruhan : Prosedur dan sistem sudah baik dalam

mencegah kesalahan dan hanya ada sedikit masalah keselamatan pasien

9. Staffing : Jumlah staf cukup untuk menyelesaikan beban kerja dan jumlah jam kerja sesuai

untuk memberikan pelayanan yang terbaik untuk keselamatan pasien

10. Ekspektasi dan Upaya Atasan dalam meningkatkan keselamatan pasien : Atasan mempertimbangkan masukan staf untuk meningkatkan keselamatan pasien, memberikan pujian bagi staf yang melaksanakan prosedur keselamatan pasien, dan tidak terlalu membesarbesarkan masalah keselamatan pasien

11. Kerja sama tim antar unit :Unit kerja di rumah sakit bekerja sama dan berkoordinasi antara satu unit dengan unit yang lain untuk memberikan pelayanan yang terbaik untuk pasien
12. Kerja sama dalam tim unit : kerja Staf saling mendukung satu sama lain, saling menghormati, dan bekerja sama sebagai

Saat evaluasi budaya keselamatan pasien, sangat penting untuk memperhatikan adanya adanya pelaporan insiden. Pelaporan insiden menjadi salah satu indicator besar yang bisa diukur bagaimana budaya keselamatan pasien yang berlangsung selama kurun waktu tertentu. Selain itu, melalui adanya pelaporan bisa diidentifikasi setiap risiko insiden yang terjadi.

Mengembangkan sistem pelaporan dan sistem analisis. Dapat dipastikan bahwa sistem pelaporan akan mengajak semua orang dalam organisasi untuk peduli akan bahaya/potensi bahaya yang dapat terjadi kepada pasien. Pelaporan insiden penting karena akan menjadi awal proses pembelajaran untuk mencegah kejadian yang sama terulang kembali, pelaporan juga dapat digunakan untuk memonitor upaya pencegahan terjadinya error sehingga diharapkan dapat mendorong dilakukannya investigasi selanjutnya.

Untuk memulai kegiatan pelaporan ini, perlu dibuat suatu sistem pelaporan insiden di rumah sakit meliputi kebijakan, alur pelaporan, formulir pelaporan dan prosedur pelaporan yang harus disosialisasikan pada seluruh karyawan. Insiden yang dilaporkan adalah kejadian yang sudah terjadi, potensial terjadi ataupun yang nyaris terjadi. Laporan insiden ini dibuat oleh semua staf rumah sakit yang pertama menemukan kejadian dan staf yang terlibat dalam suatu kejadian. Masalah yang sering muncul dalam pelaporan insiden, diantaranya adalah laporan masih dipersepsikan 
sebagai "pekerjaan tambahan" perawat, laporan sering disembunyikan/underreport karena takut disalahkan, terlambat dalam pelaporan, dan laporan miskin data karena ada budaya blame culture .

Supaya kegiatan pelaporan dapat berjalan dengan baik, karyawan/perawat perlu diberikan pelatihan mengenai sistem pelaporan insiden mulai dari maksud, tujuan dan manfaat laporan, alur pelaporan insiden ke tim KP secara internal (di rumah sakit) ataupun alur pelaporan secara eksternal (di luar rumah sakit), bagaimana cara mengisi formulir laporan insiden, kapan harus melaporkan, pengertianpengertian yang digunakan dalam sistem pelaporan dan cara menganalisa laporan.

\section{PENUTUP}

\section{Kesimpulan}

Budaya keselamatan pasien merupakan hal penting dari berbagai upaya untuk meningkatkan keselamatan pasien dan mempengaruhi kualitas pelayanan kesehatan. Budaya keselamatan adalah nilai, keyakinan, perilaku yang dianut individu dalam suatu organisasi mengenai keselamatan yang memprioritaskan dan mendukung peningkatan keselamatan.

Namun, penerapan keselamatan pasien jauh dari standar karena para tenaga kesehatan belum memiliki budaya keselamatan pasien yang terinternalisasi dalam diri mereka. Sehingga perlu dilakukan upaya untuk menanamkan budaya keselamatan pasien dengan cara promosi budaya keselamatan itu sendiri. Pelatihan tim dan executive walk rounds merupakan strategi intervensi yang cukup bermakna untuk mempromosikan keselamatan pasien

Selain itu, dalam membangun budaya keselamatan, sangat penting bagi rumah sakit untuk mengukur perkembangan budaya dengan melakukan evaluasi budaya keselamatan secara berkala. Pengukuran pertama sangat penting sebagai data dasar yang akan dipergunakan sebagai acuan penyusunan program keselamatan pasien. Evaluasi budaya keselamatan bisa dengan menjadikan Dimensi Budaya Keselamatan Pasien menjadi tolak ukurnya melalui 12 dimensi keselamatan pasien yang dikeluarkan oleh AHRQ (American Hoaspital Research and Quality) mengenai isue keselamatan pasien, medical errors, dan pelaporan insiden

\section{DAFTAR PUSTAKA}

1. Afrisya Iriviranty. (2014). Analisis Budaya Organisasi dan Budaya Keselamatan Pasien Sebagai Langkah Pengembangan Keselamatan Pasien di RSIA Budi Kemuliaan Tahun 2014. Volume 1 Nomor 3

2. Basok Buhari (2019). Budaya Keselamatan Pasien Rumah Sakit Pemerintah dan Rumah Sakit 
Swasta di Kota Jambi. Volume 3, Nomor 1, Februari 2019

3. Chen, IC, Ng, H-F \& Li, H-H 2012, 'A multilevel model of patient safety culture: cross-level relationship between organizational culture and patient safety behavior in Taiwan's hospitals', The International Journal of Health Planning And Management, vol. 27, no. 1, pp. e65-e82.

4. didesain untuk mengukur opini staf rumah Nygren, M, Roback, $\mathrm{K}$, Öhrn, A, Rutberg, H, Rahmqvist, M \& Nilsen, P 2013, 'Factors influencing patient safety in Sweden: perceptions of patient safety officers in the county councils', BMC Health Services Research, vol. 13, p. 52.

5. Feng, XQ, Acord, L, Cheng, YJ, Zeng, JH \& Song, JP 2011, 'The relationship between management safety commitment and patient safety culture', International Nursing Review, vol. 58, no. 2, pp. 249-54.

6. Forster, AJ, Dervin, G, Martin, C \& Papp, S 2012, 'Improving patient safety through the systematic evaluation of patient outcomes', Canadian Journal of Surgery, vol. 55, no. 6, pp. 418-25.

7. Iriyanto Pagala, Zahroh Shaluhiyah, Baju Widjasena (2017). Perilaku Kepatuhan Perawat Melaksanakan SOP Terhadap Kejadian Keselamatan Pasien di Rumah Sakit X Kendari. Vol 12 nomor 1.

8. Schmidt, E, Goldhaber-Fiebert, SN, Ho, LA \& McDonald, KM
2013, 'Simulation exercises as a patient safety strategy: a systematic review', Annals of Internal Medicine, vol. 158 , no. 5 pp. 42632.

9. Simamora, R. H., \&Fathi, A. (2019). The Influence Of Training Handover Based SBAR Communication For Improving Patients Safety. Indian journal of public health research \& development, 10(9), 1280-1285.

10. Slater, BL, Lawton, R, Armitage, G, Bibby, J \& Wright, J 2012, 'Training and action for patient safety: Embedding interprofessional education for patient safety within an improvement methodology', Journal of Continuing Education in the Health Professions, vol. 32, no. 2, pp. 80-9.

11. Tantri Arini (2018). Budaya Keselamatan Pasien Berbasis Pemberdayaan Struktural Dengan kepuasan Kerja Perawat. Tesis.. Universitas Airlangga Surabaya.

12. Weaver, SJ, Lubomski, LH, Wilson, RF, Pfoh, ER, Martinez, KA \& Dy, SM 2013, 'Promoting a culture of safety as a patient safety strategy: a systematic review ', Annals of Internal Medicine, vol. 158, no. 5, pp. 369-74.

13. Yennike Tri Herawati (2015). Budaya Keselamatan Pasien di Ruang Rawat Inap Rs. X Kabupaten Jember. Volume 11 Nomor 1 Maret 2015. 